\title{
Could local antibiotics be included in the treatment of acute anal fissure?
}

Banu Karapolat (D)

ABSTRACT

ORCID ID of the author: B.K. 0000-0001-5132-8266.

\section{Cite this paper as:} Karapolat B. Could local antibiotics be included in the treatment of acute anal fissure?. Turk J Surg 2018; 34(4): 286-289.

Department of General Surgery, Kanuni Training and Research Hospital, Trabzon, Turkey

\section{Corresponding Author} Banu Karapolat e-mail:banukarapolat@hotmail.com

Received: 15.08.2017 Accepted: 06.12.2017 Available Online Date: 11.09.2018

CCopyright 2018 by Turkish Surgical Association Available online at turkjsurg.com
Objective: Acute anal fissure is a very common disorder of the anorectal region. Its most widely used treatment method is the medications given in addition to conservative therapies. The objective of the present study was to investigate the effects of local metronidazole use in the treatment of acute anal fissure on the symptoms and remission processes of the patients.

Material and Methods: This was a prospective, randomized, controlled clinical study conducted on 100 consecutive patients who presented to our clinic between March 2016 and March 2017 and who were diagnosed with acute anal fissure. Patients were randomly divided into two groups of 50 persons. Patients in Group 1 were given only 5\% lidocaine pomade as a local anesthesia, and those in Group 2 were given $5 \%$ lidocaine pomade and metronidazole cream. Patients applied the medications topically to the anal margin 3 times per day for 4 weeks. Patients' demographic characteristics, such as age and gender, were recorded. All patients were invited for check-up at the end of weeks 1, 2, and 4 of treatment. The Visual Analogue Scale scores for pain and the healing status of their fissure by visual inspection, as well as any adverse effects of the drugs, were recorded. The results were compared statistically. A p-value $<0.05$ was considered significant.

Results: The mean ages of the patients were 34.2 \pm 4.1 years in Group 1 and 36.6 \pm 3.8 years in Group 2. As a result of the statistical comparison of the Visual Analogue Scale scores, there was a statistically significant difference between the two groups at the end of weeks 2 and 4 ( $p=0.004$ and $p<0.001$, respectively). In Group 1, 28 (56\%) patients recovered, but no recovery was observed in 22 (44\%) patients. In Group 2, 43 (86\%) patients recovered, whereas 7 (14\%) patients had no recovery $(p=0.004)$.

Conclusion: The topical antimicrobial treatment with metronidazole as an addition to the classical medical treatments in acute anal fissure is an effective and safe practice resulting in further reduction in pain and increased healing rate.

Keywords: Acute anal fissure, antibacterial agents, metronidazole, therapeutics

\section{INTRODUCTION}

Anal fissure is one of the most common diseases of the anorectal region that is frequently encountered in surgical practice (1). It is a longitudinal rupture of the stratified squamous epithelial tissue formed in the anoderm distal to the dentate line and is generally located on the middle line posterior to the anus $(2,3)$. Although the exact etiology is not clearly known, the factors affecting the physiopathology of anal fissure are thought to include disadvantageous anatomic structure such as tight anal sphincter and multifactorial origin, such as internal anal sphincter spasms, ischemia, infectious conditions, and local traumas due to hard stool passage, long-lasting constipation, or diarrhea.

In the treatment of acute anal fissure where a speedy and effective treatment is preferred, nitroglycerin and calcium channel blockers, such as diltiazem, are also used as first-line agents in addition to conservative treatments, such as fiber-rich diet and warm sitz baths. These reduce the internal anal sphincter tone. Local anesthesia and steroid containing pomades are also used to eliminate pain and laxatives to prevent any anal canal trauma $(3,4)$. In patients who do not respond to these medical treatments, a surgical lateral internal sphincterotomy is required as a gold standard of treatment $(3,5,6)$. Anal fissure is often accompanied by infections in many patients as the rupture is in a region with a bacterial concentration and due to personal hygiene problems. In such cases, antibiotherapy that can be used against infection in addition to the classical treatment of anal fissure may facilitate recovery of patients.

Metronidazole is a 5-nitroimidazole derivative antibiotic of a lipophilic character with a bactericidal effect particularly on anaerobic pathogen bacteria. It is widely used in clinical practice against protozoon infections as well as for the treatment of ailments where mixed pathogen microorganisms are active. The purpose of the present study was to investigate whether it is effective and safe to use a metronidazole-containing local antibiotic in reducing the symptoms and improving the recovery process when treating patients for acute anal fissure. 


\section{MATERIAL AND METHODS}

This was a prospective, randomized, controlled clinical study conducted on 100 consecutive patients who presented to the general surgery outpatient clinic of Trabzon Kanuni Training and Research Hospital between March 2016 and March 2017 were diagnosed with acute anal fissure. The major complaints of the patients were painful defecation, bleeding, constipation, diarrhea, and itching. The diagnosis of acute anal fissure was made based solely on clinical examination. The study included patients aged between 18 and 70 years who had their complaints for $<6$ weeks, whose lesions were limited to the epithelium, and who had pain in the anal region together with ulcers in the posterior anoderm without any skin tags. Patients with perianal fistula, perianal abscess, accompanying inflammatory bowel disease, and immune deficiency; receiving oral immunosuppressive drugs or steroids; with a history of hemorrhoid or hemorrhoidectomy; with a chronic disease, such as ischemic heart disease, hypertension, chronic obstructive pulmonary disease, and diabetes mellitus; who were pregnant; and with lateral or anterior localized fissures were excluded from the study.

Patients were randomly divided into two groups of 50 persons by choosing a color-coded card in thick white envelopes. Patients received the medication from an assistant staff who saw the color of the cards. The researcher was blinded to the medicine administered to each patient. Patients in Group 1 were given only $5 \%$ lidocaine pomade (Anestol 5\% pomade; Sandoz Ilaç San. ve Tic. A.Ş., Istanbul, Turkey) as a local anesthesia, and those in Group 2 were given 5\% lidocaine pomade (Anestol 5\% pomade) and metronidazole cream (Roza cream; ORVA İlaç San. ve Tic A.Ş., Izmir, Turkey). All patients underwent detailed anamnesis and physical examination before treatment was commenced. All patients were instructed to apply a pea-sized amount of each drug topically to their anal margins 3 times per day for 4 weeks. They were also advised to follow a fiber-rich diet, take the laxatives, and have a 15-minute warm bath 3 times per day. Patients' demographic characteristics, such as age and gender, were recorded. All patients were physically examined at the end of weeks 1,2 , and 4 of treatment. Complaints of pain during defecation were assessed using the Visual Analogue Scale (VAS). Clinical healing was considered as complete reepithelialization of the anal canal mucosa and closure of the fissure with no erythema or inflammation and elimination of patient complaints. The VAS score was used to measure pain. The scale was divided into 10 equal parts, with 0 to denote no pain and 10 to denote unbearable pain. All patients'VAS scores for pain and healing of fissure by visual inspection, as well as any adverse effects of the drugs, were recorded and statistically compared.

The study protocol was approved by the local ethics committee. All patients were provided with adequate verbal information about the study. Written informed consent was obtained from all patients. All patient data were kept confidential. The study was conducted according to the Declaration of Helsinki as revised in 2000 .

\section{Sample size}

The sample size was determined post hoc. At the end of the study, the healing rate was found to be $56 \%$ in Group 1 and
$86 \%$ in Group 2. Considering the healing rate prevalence as $86 \%$, the sample size was calculated as 47 for one group at $95 \%$ confidence interval with $10 \%$ deviation, presuming type 1 error as 0.05 . Calculation of the sample size was performed by the OpenEpi version 3 (http://www.openepi.com/SampleSize/SSPropor.htm).

\section{Statistical Analyses}

All statistical data analyses were performed using the Statistical Package for the Social Sciences (SPSS) version 15.0 for Windows software (SPSS Inc., Chicago, IL, USA). Descriptive statistics were used for comparisons. Student's t test, Mann-Whitney $U$ test, and chi-square test were used to assess independent samples. A p-value $<0.05$ was accepted as statistically significant.

\section{RESULTS}

There were $40(80 \%)$ female and $10(20 \%)$ male patients in Group 1 and 38 (76\%) female and 12 (24\%) male patients in Group 2. The mean ages of the patients were 34.2 \pm 4.1 years in Group 1 and 36.6 3.8 years in Group 2. No statistically significant difference was found between the two groups with respect to gender distributions and mean ages $(p=0.412$ and $p=0.510$, respectively). An assessment of the patient complaints revealed that the most common complaint was pain and bleeding during defecation. Table 1 shows the frequencies and percentages of patient complaints in the groups. Table 2 shows the median duration of symptoms of patients. All patients completed the treatment period without any problems. No side effects or complications associated with the medications used occurred in any of the patients.

The mean VAS scores of the patients at the time of presentation to the hospital (pretreatment) were 7.8 \pm 0.9 in Group 1 and $7.9 \pm 0.7$ in Group $2(p=0.417)$. The mean VAS scores of the patients at the end of week 1 were $4.6 \pm 1.0$ in Group 1 and $4.3 \pm 0.9$ in Group 2 ( $p=0.151)$. The mean VAS scores of the patients at the end of week 2 were $3.3 \pm 1.3$ in Group 1 and 2.6 \pm 1.1

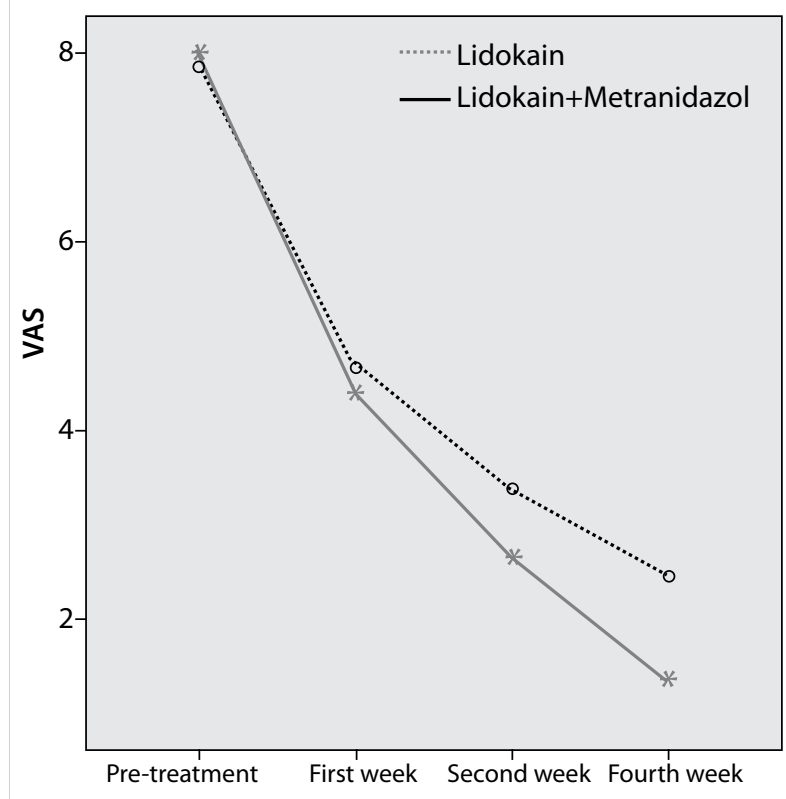

Figure 1. Reduction rates of the VAS scores of Group 1 and Group 2 during the study 


\begin{tabular}{|c|c|c|}
\hline & Group $1(n=50)$ & Group $2(n=50)$ \\
\hline $\begin{array}{l}\text { Pain during } \\
\text { defecation (days) }\end{array}$ & $50(100)$ & $50(100)$ \\
\hline Bleeding (days) & $40(80)$ & $37(74)$ \\
\hline Constipation (days) & $33(66)$ & $35(70)$ \\
\hline Diarrhea (days) & $7(14)$ & $8(16)$ \\
\hline Itching (days) & $18(36)$ & $20(40)$ \\
\hline
\end{tabular}

Datas are presented as $\mathrm{n}(\%)$

\begin{tabular}{|lcc|}
\hline \multicolumn{3}{|c|}{ Table 2. Median duration of symptoms of patients } \\
\hline & $\begin{array}{c}\text { Group 1 } \\
\text { mean (range) }\end{array}$ & $\begin{array}{c}\text { Group 2 } \\
\text { mean (range) }\end{array}$ \\
\hline Pain during defecation (days) & $21(9-41)$ & $16(5-38)$ \\
\hline Bleeding (days) & $11(1-27)$ & $9(3-19)$ \\
\hline Constipation (days) & $29(14-38)$ & $32(11-40)$ \\
\hline Diarrhea (days) & $8(7-16)$ & $5(3-9)$ \\
\hline Itching (days) & $12(5-26)$ & $18(5-32)$ \\
\hline
\end{tabular}

in Group $2(p=0.004)$. The mean VAS scores of the patients at the end of week 4 were 2.47 in Group 1 and 1.36 in Group 2 with a median of 1 (interquartile range (IQR): 1-4) in Group 1 and a median of 1 (IQR: $1-1)$ in Group $2(p<0.001)$.

A statistical comparison of the VAS scores showed that there was a statistically significant difference between the two groups at the end of weeks 2 and 4 (Figure 1).

In Group 1, 5 (10\%) patients had recovery at week 2 and 23 (46\%) patients at week 4 with no recovery seen in 22 (44\%) patients. In Group 2, 9 (18\%) patients had recovery at week 2 and $34(68 \%)$ patients at week 4 with no recovery seen in 7 (14\%) patients. There was a statistically significant difference between these data $(p=0.004)$.

\section{DISCUSSION}

Acute anal fissure involves high prevalence and great discomfort and equally affects both women and men. We think that the reason why there were more female than male patients in the present study was because the surgeon who performed the anal examinations and treatments of the patients was a woman. The sociocultural characteristics of female patients in our country and particularly in our region call for conservative attitude and embarrassment associated with physical examination for perianal disorders, urging women to prefer a female surgeon. Acute anal fissure is mostly seen in individuals aged between 20 and 40 years. We found that the majority of the patients in our study were $30-40$ years old, which is compatible with the literature $(1,2)$.

The typical symptoms of presentation in acute anal fissure are proctalgia and bleeding (7). Pain is usually sharp and intensifies during defecation. Bleeding may accompany painful defecation. Rectal bleeding is bright red in color and generally occurs in minor amounts (8). The initial complaints of our patients included mostly pain during and after defecation, bleeding, and constipation. These data are compatible with those in the literature $(3,7)$.
In the present study, we found that the use of local metronidazole in combination with local anesthesia drugs prescribed as a first-line therapy for acute anal fissure resulted in a marked reduction of pain symptoms especially after week 2 of treatment. The rupture occurring at the anoderm causes spasm at the internal sphincter located right under the fissure tissue and increases resting pressures of the anal canal, leading to pain and decrease regional blood flow. As a result, pain, spasm, and ischemia cycles turn the rupture into a difficult-to-cure wound, resulting in chronic anal fissure (3). In view of this information, the idea that eliminating pain effectively during the initial treatment will break the vicious cycle mentioned above and result in healing has led to the widespread use of local anesthesia drugs first in the medical treatment. A previous study showed that $40 \%-60 \%$ healing occurs with the use of local lidocaine in patients with acute anal fissure (9). Our results were similar to these except that the healing rate was $56 \%$ in the group where lidocaine was used alone. Considering that approximately half of the patients have not recovered using this treatment, it is obvious that elimination of other factors that may be effective in the physiopathology of acute anal fissure will increase the healing rate. We think that one of these important factors is local inflammation and infection as we consider the current flora of the region and the microorganisms in stool (Gram-positive/ Gram-negative anaerobic bacteria or Gram-negative aerobic bacteria). In fact, a previous study stated that the infections in this region may be one of the main causes of acute anal fissure (10). Occasionally, even an infection localized in the subcutaneous area at the anal fissure region that progresses subclinically may cause the fissure symptoms to become chronic (11). As general information, if any wound is accompanied by ischemia and infection, healing of the wound is delayed. Owing to all these reasons, we included metronidazole, which has an effective spectrum on the above-mentioned microorganisms, in the first-line treatment of acute anal fissure in the present study. What happened here was that decreasing the bacterial load with topical antibacterial treatment accelerated fissure healing. Owing to this, the healing rate increased to $86 \%$ in Group 2. Keeping the local infection under control led to a decrease in pain that was associated with sphincter spasm aggravated by inflammation. This was demonstrated by decreases in the VAS scores at the end of weeks 2 and 4 of treatment. A review of the literature revealed that there was improvement in the symptoms in a pilot study involving local application of povidone-iodine solution in chronic anal fissure (12). Moreover, with oral ciprofloxacin and ornidazole that were used for a period of only 5 days, significant symptomatic relief was achieved in $>90 \%$ of cases with chronic anal fissure (13). The same authors reported in 2014 that the local application of ornidazole cream for 3 months in addition to the above regimen sustained the symptomatic benefits achieved and helped cure chronic anal fissure in up to $90 \%$ of patients (14). Grekova et al. (10) found that patients with chronic anal fissure and anaerobic bacteria in their swabs who received topical metronidazole treatment experience rapid relief of pain and anal sphincter spasm along with enhanced fissure healing (healing rate: 95.6\%). To our knowledge, this is the first study on the use of local antibiotics in acute anal fissure. All these results show that infection has a major role in the etiopathogenesis of anal fissure. For this reason, we think that local antibiotic use before 
the condition becomes chronic will shorten the recovery time and increase the healing rates in cases with acute anal fissure.

The limitations of the present study include short follow-up time, small sample sizes of the two groups, and the study having been conducted in a single site. Therefore, the long-term recurrence rates of the patients remain unknown. Nevertheless, we think that our study adds useful data to the treatment of acute anal fissure. Further multicenter clinical studies involving broad patient populations, longer follow-up times, and recurrence rates will aid to understand the efficacy and safety of metronidazole in the treatment of acute anal fissure.

\section{CONCLUSION}

Although various non-surgical and surgical treatment methods have been used, an ideal treatment method for acute anal fissure is still debatable. The topical antimicrobial treatment with metronidazole in addition to conventional medical treatments is an effective, easy-to-use, safe, fast and comfortable practice that enables further reduction of anal fissure pain and increases the healing rate. With this promising treatment, cases with acute anal fissure can be prevented from becoming chronic, and patients can be saved from being subject to future surgical interventions that involve high complication rates.

Ethics Committee Approval: Ethics committee approval was received for this study from the Ethics Committee of Kanuni Training and Research Hospital.

Informed Consent: Written informed consent was obtained from patient who participated in this study.

Peer-review: Externally peer-reviewed.

Conflict of Interest: The author has no conflicts of interest to declare.

Financial Disclosure: The author declared that this study has received no financial support.

\section{REFERENCES}

1. Vaithianathan R, Panneerselvam S. Randomised Prospective Controlled Trial of Topical 2\% Diltiazem Versus Lateral Internal Sphincterotomy for the Treatment of Chronic Fissure in Ano. Indian J Surg 2015; 77(Suppl 3): 1484-1487. [CrossRef]
2. Motie MR, Hashemi P. Chronic Anal Fissure: A Comparative Study of Medical Treatment Versus Surgical Sphincterotomy. Acta Med Iran 2016; 54: 437-440.

3. Coskun A, Uzunkoy A, Akinci F. The treatment efficacy of medical sphincterotomy with glycerol trinitrate on acute and chronic anal fissures. Ulus Cerrahi Derg 2000; 16: 176-181.

4. Uluutku H, Akin ML, Erenoglu C, Yildiz M, Urkaya N, Celenk T. Efficacy of nifedipine, glyceryl trinitrate and botulinum toxin in treatment of chronic anal fissure. Ulus Cerrahi Derg 2001; 17: 343350.

5. Colak T, Ipek T, Kanik A, Aydin S. A randomized trial of botulinum toxin vs lidocain pomade for chronic anal fissure. Acta Gastroenterol Belg 2002; 65: 187-190.

6. Yakoot M, Abdel Salaam M. Study of efficacy and safety of a new local cream ('healer') in the treatment of chronic anal fissure: a prospective, randomized, single-blind, comparative study. Arq Gastroenterol 2009; 46: 179-182. [CrossRef]

7. Sánchez Romero A, Arroyo Sebastián A, Pérez Vicente F, Serrano Paz P, Candela Polo F, Tomás Gómez A, et al. Open lateral internal anal sphincterotomy under local anesthesia as the gold standard in the treatment of chronic anal fissures. A prospective clinical and manometric study. Rev Esp Enferm Dig 2004; 96: 856-863. [CrossRef]

8. Khaledifar B, Mahmoudi MY, Mobasheri M. A Double-Blind Randomized Trial Comparing the Effectiveness and Safety of Nifedipine and Isosorbide Dinitrate in Chronic Anal Fissure. Malays J Med Sci 2015; 22: 42-49.

9. Higuero T. Update on the management of anal fissure. J Visc Surg 2015; 152(2 Suppl): S37-S43. [CrossRef]

10. Grekova NM, Maleva EA, Lebedeva Y, Bordunovsky VN, Telesheva LF, Bychkovskikh VA. The effects of topical application of metronidazole for treatment of chronic anal fissure: A randomized, controlled pilot study. Indian J Gastroenterol 2015; 34: 152-157. [CrossRef]

11. Garg P. Local and Oral Antibiotics with Avoidance of Constipation (LOABAC) Treatment for Anal Fissure: a New Concept in Conservative Management. Indian J Surg 2016; 78: 80. [CrossRef]

12. Durai R, Razvi A, Hin PN. Novel use of povidone iodine in fissurein-ano. Singapore Med J 2010; 51: 837-838.

13. Garg P, Lakhtaria P, Nalamati S, Gupta V, Thakur J. Chronic anal fissure: is it an infection in a physically deformed lesion?-a new insight into an old plight. In Annual conference of American Society of Colon Rectum Surgeons (ASCRS). San Antonio 2012.

14. Garg P, Lakhtaria P. Non-surgical management of chronic fissurein-ano with high success rate: a simple novel concept in the treatment of chronic fissure-in-ano. In Annual conference of American Society of Colon Rectum Surgeons (ASCRS). Fort Laurderdale 2014. 